\title{
Piercing technique for recanalization of pancreaticojejunal obstruction through the endoscopic ultrasound-guided pancreatic duct drainage route
}

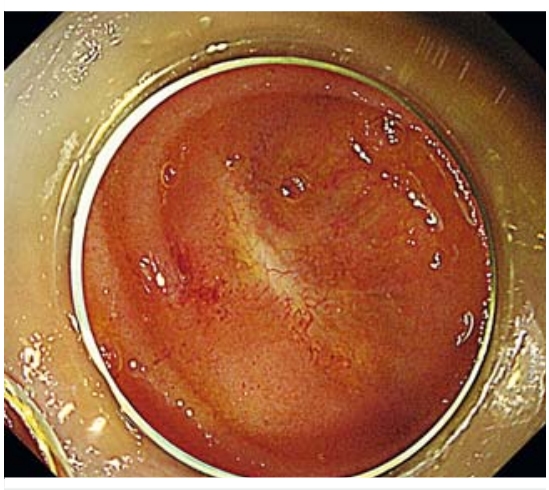

- Fig. 1 Image during balloon enteroscopy-assisted endoscopic retrograde pancreatography showing that the pancreaticojejunal anastomosis could not be found although, from the computed tomography $(\mathrm{CT})$ and magnetic resonance cholangiopancreatography (MRCP) scans, it was considered to be located at the end of the jejunum.

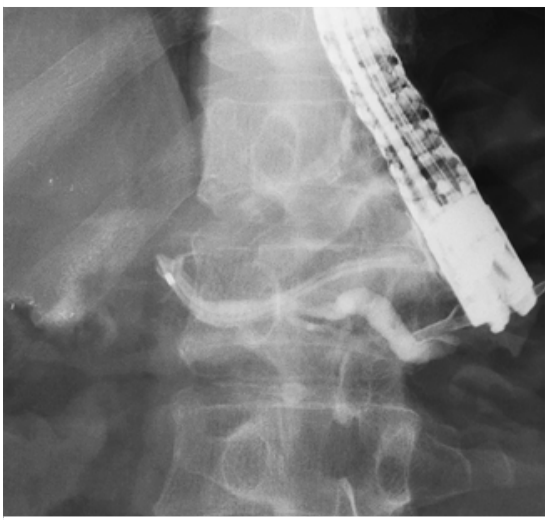

- Fig. 2 Radiographic image showing that the tip of the catheter was directed to the lumen of the jejunal limb, but no contrast media flowed into the jejunum and the guidewire could not be passed through the anastomosis.

Endoscopic ultrasound-guided pancreatic duct intervention is considered to be the most difficult procedure and requires various techniques to achieve successful treatment, particularly in patients who have undergone pancreatectomy [1]. We report a case of successful recanalization of a complete anastomotic ob-

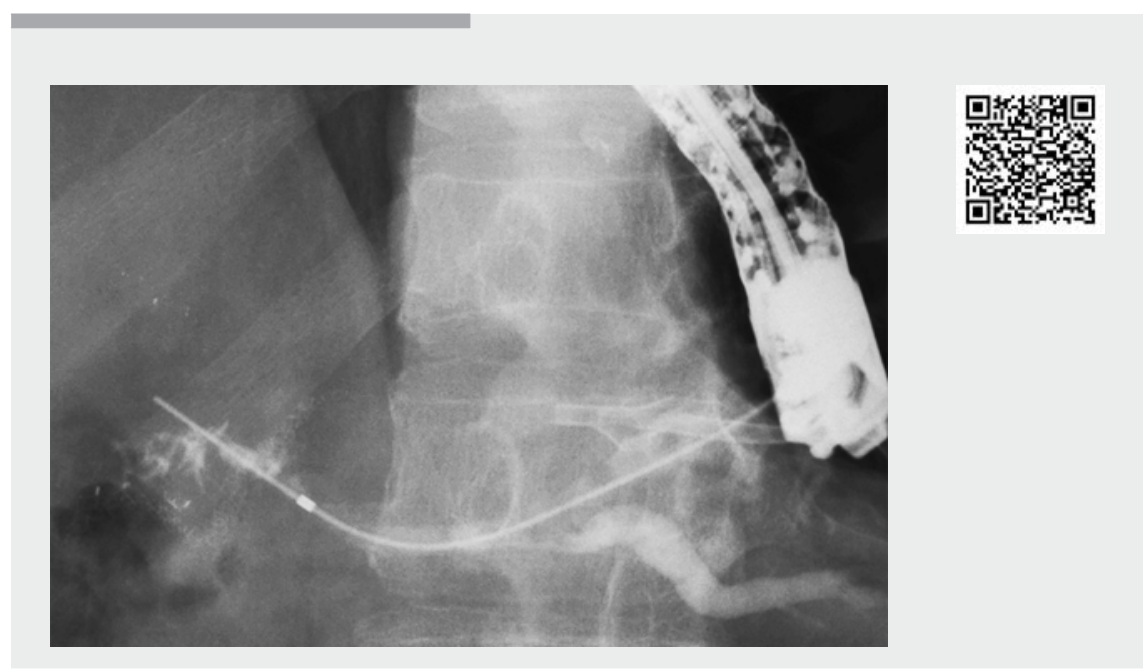

Video 1 Recanalization of a pancreaticojejunal obstruction by puncturing with the stiff back end of a guidewire through the endoscopic ultrasound-guided pancreatic duct drainage route.

struction after pancreaticojejunostomy using a piercing technique ( $\vee$ Video 1$)$. A 64-year-old man underwent pancreaticoduodenectomy for a pancreatic neuroendocrine tumor; however, he suffered from recurrent pancreatitis owing to pancreaticojejunostomy dysfunction. Initially, we attempted balloon enteroscopy-assisted endoscopic retrograde pancreatography, but we were unable to locate the anastomosis ( $\triangleright$ Fig. 1). We then attempted antegrade stenting from the stomach by endoscopic ultrasound-guided pancreatic duct drainage (EUS-PD), but we could not pass a guidewire through the anastomosis. Therefore, we deployed a plastic stent from the main pancreatic duct to the stomach.

We made a further attempt at recanalization through the EUS-PD route 2 months later. Pancreatography was performed, but no contrast media flowed into the jejunum and the guidewire could not be passed through the anastomosis ( $>$ Fig. 2). We therefore reviewed the computed tomography (CT) and magnetic resonance cholangiopancrea- tography (MRCP) images ( $>$ Fig.3), and considered that the tip of the catheter was directed to the lumen of the jejunal limb, and confirmed that there were no major blood vessels around the anastomosis. Accordingly, we punctured the anastomosis using the stiff back end of a 0.035-inch hydrophilic guidewire (Radifocus; Terumo Corp., Tokyo, Japan) and successfully achieved recanalization. After performing balloon dilation, we placed a plastic stent without any adverse events ( $>$ Fig. 4 and $>$ Fig. 5).

Puncture with the stiff back end of a guidewire has been previously reported as a piercing technique [2,3]. In the EUS-PD procedure, recanalization of the complete anastomotic obstruction is key to a successful treatment. Although the use of other imaging modalities to initially confirm the correct piercing direction and ensure that adverse events will be minimal is indispensable, this technique can be an effective tool for patients where recanalization is difficult.

Endoscopy_UCTN_Code_TTT_1AS_2AD 


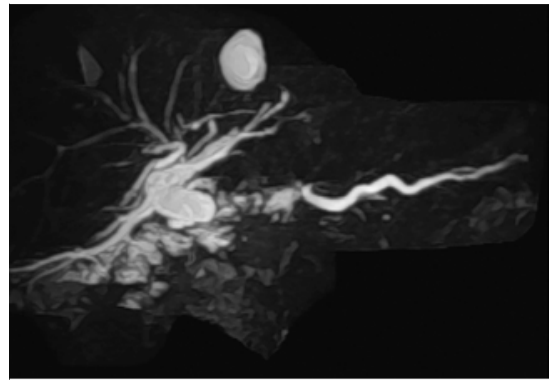

- Fig. 3 Magnetic resonance cholangiopancreatography (MRCP) image before the onset of pancreatitis.

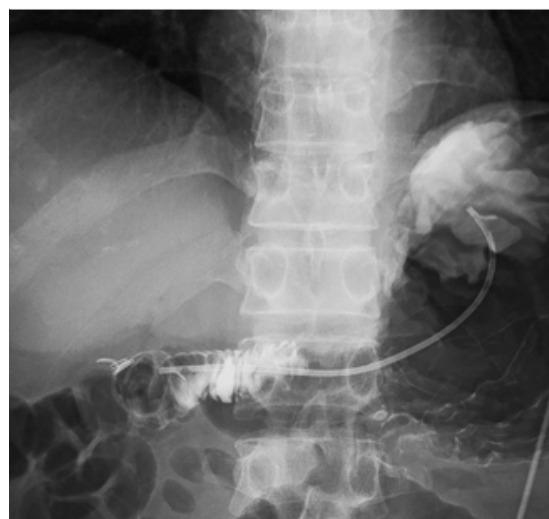

- Fig. 4 Radiographic image showing a transmural stent placed between the jejunum and the stomach.

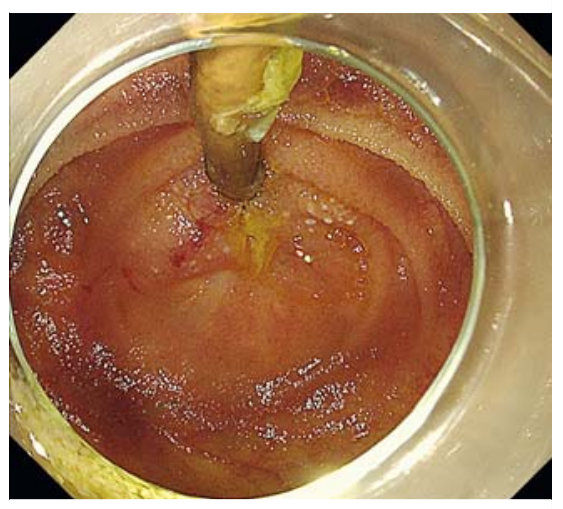

- Fig. 5 Endoscopic image 1 month later showing that the stent was present at the end of the jejunum.

\section{Acknowledgments}

We thank Dr. Edward Barroga (http://orcid.org/ 0000-0002-8920-2607), Medical Editor and Professor of Academic Writing at St. Luke's International University for reviewing and editing the manuscript.

\section{Competing interests}

A. Katanuma has received lecture fees from Olympus Co., Tokyo Japan; he is currently an Associate Editor for Digestive Endoscopy. The remaining authors declare that they have no conflict of interest.

The authors

Tatsuya Ishii, Tsuyoshi Hayashi, Kuniyuki Takahashi, Toshifumi Kin, Akio Katanuma Center for Gastroenterology, Teine Keijinkai Hospital, Sapporo, Hokkaido, Japan

\section{Corresponding author}

\section{Tatsuya Ishii, MD}

Center for Gastroenterology, Teine Keijinkai Hospital, 1-40, 12-chome, 1-jou, Maeda, Teine-ku, Sapporo 006-8555, Hokkaido, Japan

Fax: +81-11-6852967

ttyisi141@outlook.com

\section{References}

[1] Nakai Y, Kogure H, Isayama H et al. Endoscopic ultrasound-guided pancreatic duct drainage. Saudi J Gastroenterol 2019; 25 : 210-217

[2] Toyonaga H, Hayashi T, Katanuma A. Piercing technique via cholangioscopy for the reconstruction of complete anastomotic obstruction after choledochojejunostomy. Dig Endosc 2020. doi:10.1111/den.13664

[3] Kim EH, Lee HG, Oh JS et al. Extraluminal recanalization of bile duct anastomosis obstruction after liver transplantation. J Vasc Interv Radiol 2018; 29: 1466-1471
Bibliography

Endoscopy 2021; 53: E134-E135

DOI 10.1055/a-1216-0593

ISSN 0013-726X

published online 5.8.2020

(C) 2020. Thieme. All rights reserved.

Georg Thieme Verlag KG, Rüdigerstraße 14, 70469 Stuttgart, Germany

\section{ENDOSCOPY E-VIDEOS}

https://eref.thieme.de/e-videos

回的回 Endoscopy E-Videos is a free 然部 靣转: on interesting cases and new

techniques in gastroenterological endoscopy. All papers include a high quality video and all contributions are freely accessible online.

This section has its own submission website at https://mc.manuscriptcentral.com/e-videos 